\title{
Characterization of Deficiencies in the Frequency Domain Forced Response Analysis Technique for Turbine Bladed- Disks
}

\author{
Andrew M. Brown ${ }^{1}$ and Preston Schmauch ${ }^{2}$ \\ NASA/Marshall Space Flight Center, Huntsville, Al,35801
}

\begin{abstract}
Turbine blades in rocket and jet engine turbomachinery experience enormous harmonic loading conditions. These loads result from the integer number of upstream and downstream stator vanes as well as the other turbine stages. The standard technique for forced response analysis to assess structural integrity is to decompose a CFD-generated flow field into its harmonic components, and to then perform a frequency response analysis at the problematic natural frequencies. Recent CFD analysis and water-flow testing at NASA/MSFC, though, indicates that this technique may miss substantial harmonic and non-harmonic excitation sources that become present in complex flows. These complications suggest the question of whether frequency domain analysis is capable of capturing the excitation content sufficiently. Two studies comparing frequency response analysis with transient response analysis, therefore, have been performed. The first is of a bladed disk with each blade modeled by simple beam elements. It was hypothesized that the randomness and other variation from the standard harmonic excitation would reduce the blade structural response, but the results showed little reduction. The second study was of a realistic model of a bladed-disk excited by the same CFD used in the $\mathbf{J} 2 \mathrm{X}$ engine program. The results showed that the transient analysis results were up to $10 \%$ higher for "clean" nodal diameter excitations and six times larger for "messy" excitations, where substantial Fourier content around the main harmonic exists.
\end{abstract}

\section{Nomenclature}

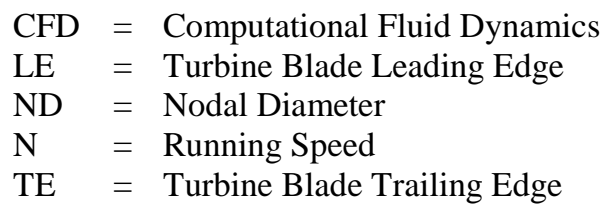

\section{Introduction}

U as turbine blades experience enormous harmonic loading conditions, especially those in rocket engines. These loads result from the immediately upstream nozzles or vanes and downstream stator vanes as well as from nonadjacent stages. Assessing the blade structural integrity is a complex task requiring an initial characterization of whether resonance is possible and then performing a forced response analysis if that condition is met. The standard technique for forced response analysis in rocket engine turbines is to decompose a flow field that was generated using computational fluid dynamics (CFD) into its harmonic components, and to then perform a frequency response analysis at the problematic natural frequencies using cyclically symmetric structural dynamic models. Recent CFD analysis and water-flow testing at NASA/MSFC, though, indicates that this technique may miss substantial harmonic and non-harmonic excitation sources that become present in complex flows. This complex content can only be captured by a CFD flow field encompassing at least an entire revolution of the rotor. A substantial development effort to create a series of software programs to enable application of the $360^{\circ}$ forcing function in a

\footnotetext{
${ }^{1}$ Aerospace Technologist, Structural Dynamics, Propulsion Structural \& Dynamic Analysis, ER41, AIAA Senior Member.

${ }^{2}$ Aerospace Technologist, Fluid Dynamics, Propulsion Fluid Dynamic Analysis, ER42
} 
frequency response analysis on cyclic symmetric models has been completed ${ }^{1}$, but the question still remains whether the frequency response analysis itself is capable of capturing the excitation content sufficiently.

Therefore, two studies comparing frequency response analysis with transient response analysis of bladed-disks undergoing this complex flow environment have been performed. In this context, a transient analysis calculates the response to the complete excitation function in the temporal domain. These models are intended to be representative of the response of realistic bladed disks, so the dimensions are roughly equivalent to the $\mathrm{J} 2 \mathrm{X}$ rocket engine $1^{\text {st }}$ stage fuel pump turbine. A hypothesis going into the analysis was that perhaps the frequency response was enforcing a temporal periodicity that did not really exist, and so therefore it would overestimate the response. As high dynamic response is a considerable source of stress in the $\mathrm{J} 2 \mathrm{X}$, examining this concept could potentially be beneficial for the program.

The first set of analyses examine a bladed disk with each blade modeled by simple beam elements and the disk modeled with plates (using the finite element code MSC/NASTRAN) in order to focus on the disk-dominated modes, and to enable analyses that can be quickly performed and adjusted. This model is a first step in identifying response differences between transient and frequency forced response analysis techniques. The second study assesses this difference using a much more realistic solid model of a bladed-disk in order to evaluate the effect of the spatial variation in loading on blade-dominated modes.

The literature in this subject is essentially limited to analyses using either the frequency domain or transient techniques, and does not compare the two. Misek, et.al, describe the forced response analysis of a bladed-disk in detail, but only mention that a frequency response technique is adequate because the forcing function is substantially harmonic $^{2}$. The frequency domain technique is also used in a number of other studies, with no mention of its accuracy compared to a transient analysis ${ }^{3},{ }^{4}$. This research is therefore a new contribution to practical structural dynamic analysis of gas turbines.

\section{Results and Discussion}

\section{A. Blade Beam Model Analyses}

The blade-beam model consists of plate elements representing a 20 in diameter, 1 in thick disk, and 694 in X 1 in X 0.1 in blades each represented by 4 beam elements. The first harmonic of the upstream nozzle count on the fuel pump of the J2X causes the $5^{\text {th }}$ nodal diameter (ND) modes to be excited, and the downstream vanes excite the $12^{\text {th }}$ ND modes, as explained by Tyler and Sofrin ${ }^{5}$ and identified using the spatial aliasing chart shown in Table 1 . Only nodal diameter modes equal to or less than half the number of blades are possible in a cyclically symmetric system, so combinations exceeding that value are marked N/A in the chart.

Table 1. Blade Nodal Diameter Spatial Aliasing Charts for Upstream and Downstream Excitation.

\begin{tabular}{|c|c|c|c|c|}
\hline $\begin{array}{l}\text { Upstream Nozzle } \\
\text { Multiples }\end{array}$ & \multirow[t]{2}{*}{37} & \multirow[t]{2}{*}{74} & \multirow[t]{2}{*}{111} & \multirow[t]{2}{*}{148} \\
\hline Blade multiples & & & & \\
\hline 69 & 32 & -5 & N/A & N/A \\
\hline 138 & N/A & N/A & 27 & -10 \\
\hline 207 & N/A & N/A & N/A & N/A \\
\hline
\end{tabular}

\begin{tabular}{|c|c|c|c|c|}
\hline $\begin{array}{l}\text { Downstream } \\
\text { Stator Multiples }\end{array}$ & \multirow[t]{2}{*}{7} & \multirow[t]{2}{*}{114} & \multirow[t]{2}{*}{171} & \multirow[t]{2}{*}{228} \\
\hline Blade multiples & & & & \\
\hline 69 & 12 & N/A & N/A & N/A \\
\hline 138 & N/A & 24 & -33 & N/A \\
\hline 207 & N/A & N/A & N/A & -21 \\
\hline
\end{tabular}

A modal analysis was therefore performed on the beam/plate model to identify the 5ND bladed-disk mode to be excited at resonance, which is found to be at $40,167 \mathrm{hz}$ (see Fig. 1). To perform the frequency response analysis, a CFD analysis encompassing four complete rotor revolutions was performed for the real turbine and scaled in time such that the applicable primary excitation temporal Fourier component $\mathrm{F}_{\mathrm{o}} \mathrm{e}^{\mathrm{i} \Omega \mathrm{t}}$ has a frequency equal to the mode of interest, and the complex loading (real and imaginary parts) of the component is applied in the frequency response NASTRAN solution. This analysis is very quick because it uses the modal transformation

$$
\{u\}=[\Phi]\{q\}
$$

to decompose the very large model into modal components $\{q\}$. The response can then be calculated by superimposing the modal single-frequency responses each calculated using the standard complex single degree of freedom frequency response equation 


$$
q(t)=\bar{H}(\Omega) \bar{U}_{\text {static }}=\left[\frac{1-\Omega / \omega_{i}{ }^{2}}{\left(1-\Omega / \omega_{i}{ }^{2}\right)^{2}}+i \frac{-2 \zeta^{\Omega} / \omega_{i}}{\left(1-\Omega / \omega_{i}\right)^{2}}\right] \frac{F_{o} e^{i \Omega t}}{\lambda_{i}^{2}} .
$$

The fourier components of the loading on each blade at the modal frequencies of interest were isolated and applied to the model at not only the resonant frequency but a bandwidth about that frequency to see if potential frequency content in the pressure signal not at $74 \mathrm{~N}$ would excite other modes. The peak values of the complex magnitude of the axial response for the highest responding nodes are shown in Fig. 2. Comparisons between the transient and frequency response results are only possible for a translational component of the displacement because of the requirement to make negative peak to positive peak calculations in the transient response, as discussed below.
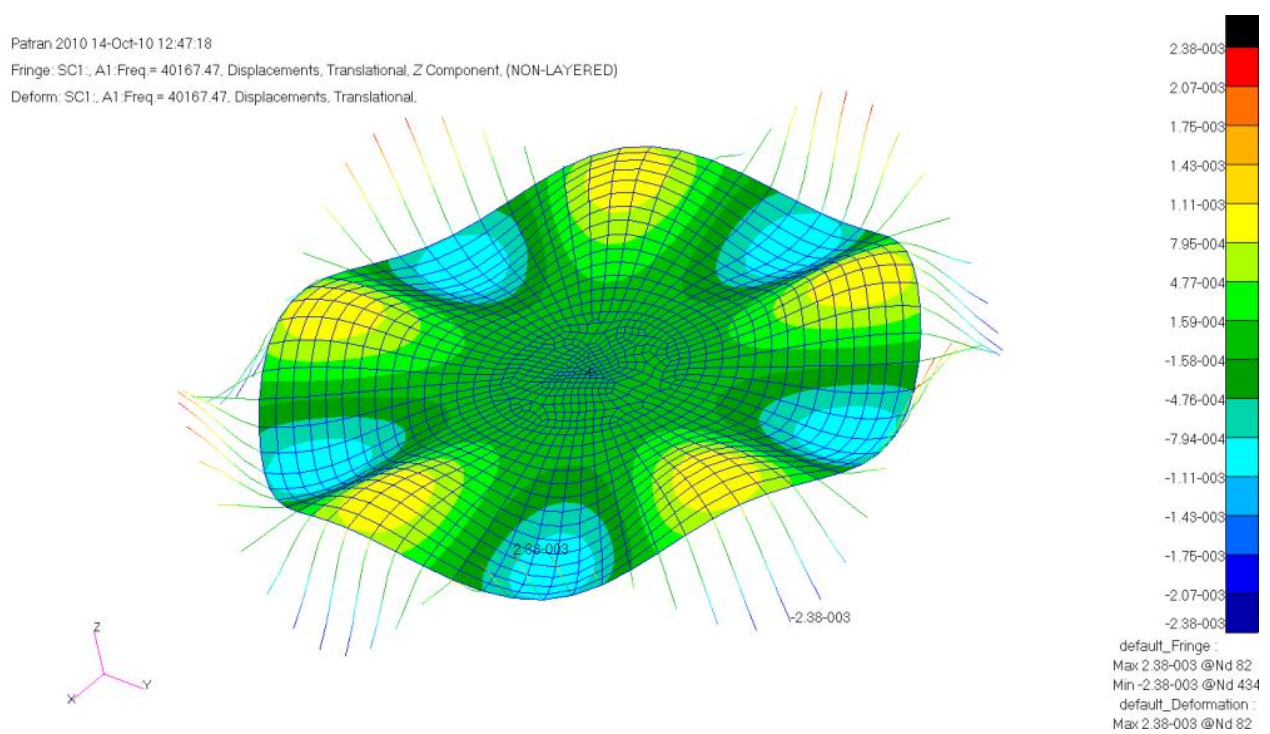

Figure 1. Beam/Plate Bladed Disk Model, 5ND mode at $40167 \mathrm{hz}$

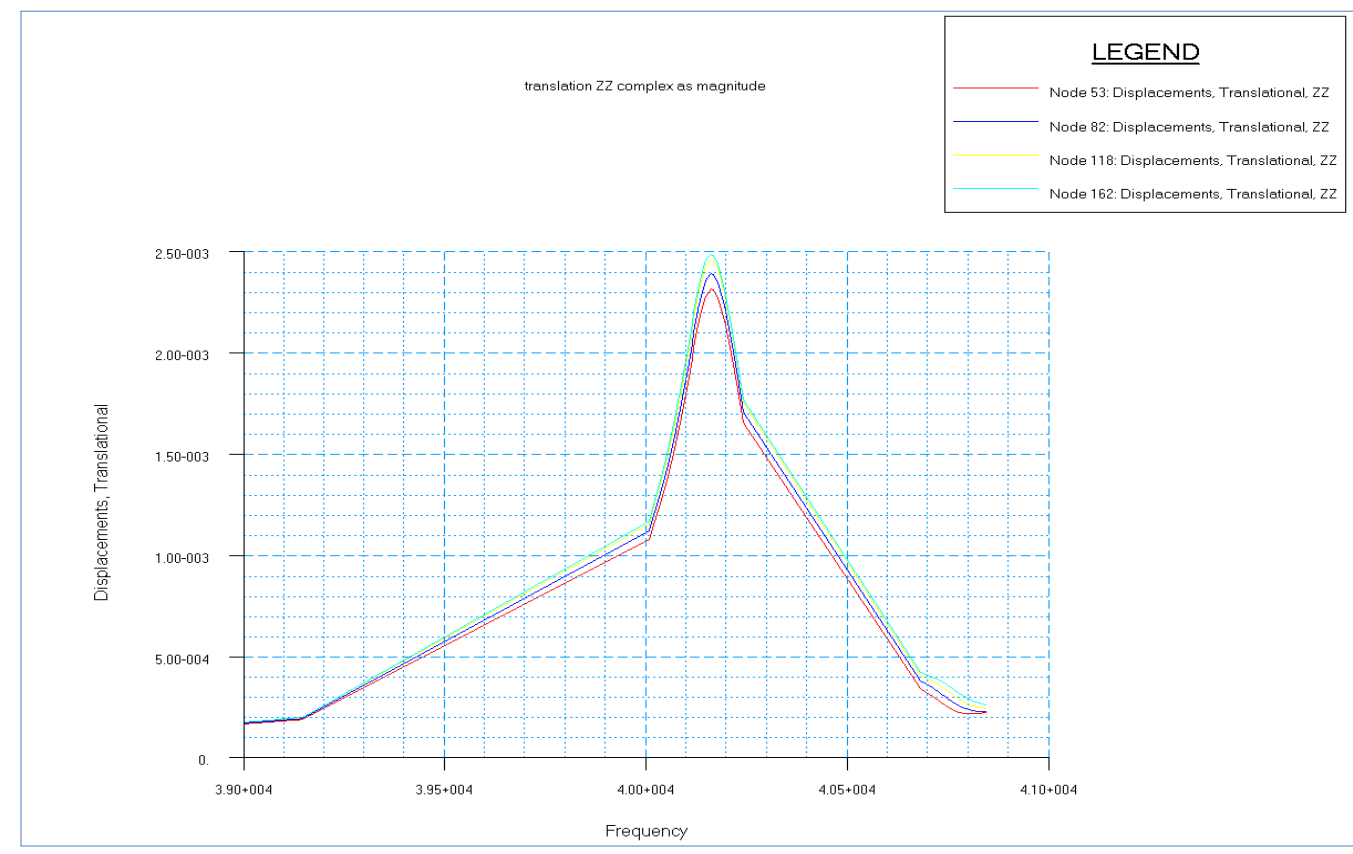

Figure 2. Peak Frequency Response of Highest Responding Nodes in Beam/Plate model 
The transient analysis was then performed. As this type of analysis typically uses a time marching numerical integration scheme, it is significantly more computer-CPU intensive than frequency response analyses, and so in general is not tractable for realistic high-fidelity solid finite element models of bladed-disks. The main difficulty for this model was creating the NASTRAN format for different high-resolution time histories on each of the blades.

The process for interpreting the results is as follows: 1) plot entire time history of the blade tip node responses for a $1 / 5$ sector of the bladed-disk (corresponding to the 5ND mode shape); 2) Identify which node has the highest response; 3) Subtract out the mean response that represents the static load component, which is included in the transient loading but not the frequency response; 4) Since the response is somewhat random in nature, calculate the statistics of the peaks of the response; 5) Apply the $2 \sigma$ value as the design value for fatigue calculations (and comparison with other methods), since it has been suggested that a sinusoid of this amplitude will produce the equivalent damage as a full Rayleigh distribution of a narrow-band random signal (envelope of Rayleigh peaks shown in Fig. 3).

For this case, the node with the highest transient axial response was node 82, which has a mean-to-peak value of 0.00345 " and a $2 \sigma$ value of displacement is .0032 ". The frequency response peak is .0024 ", a difference of $-25 \%$. These results are opposite of what was hypothesized. A promising explanation for the difference is the contributions from the response to non-integer multiples of the frequency components of the excitation close to the fundamental excitation of $74 *$ running speed $\mathrm{N}$ (called sidebands), which is all that is used in the frequency response analysis. Since four complete revolutions were processed, a discrete fourier decomposition will have a bin bandwidth of N/4; the $74 \mathrm{~N}$ energy is therefore in the $4 * 74=296$ 'th bin. These effects are investigated by taking the top three non-trivial nearby components, bins 294,295 , and 297 , corresponding to $73.5 \mathrm{~N}, 73.75 \mathrm{~N}$, and $74.25 \mathrm{~N}$ (see Fig. 4), and performing frequency response analyses using those excitation amplitudes at the slightly off-resonant frequencies. If random phasings of the off-resonant results are assumed, the equation showing the sum of the components is

$$
\begin{aligned}
x(t) & =0.000361 \operatorname{Cos}\left[\frac{\pi}{6}-238200.6 \mathrm{t}\right]+0.000369 \cos [236596.6 \mathrm{t}]+0.0024 \operatorname{Sin}[237398.66 \mathrm{t}]+ \\
& 0.0000458 \operatorname{Sin}\left[\frac{\pi}{4}+240606.7 \mathrm{t}\right]
\end{aligned}
$$

which has a maximum value of 0.0026605 over the interval studied, still $18.6 \%$ below the transient results, so this does not appear to explain the discrepancy. The resolution of this question will require future study. However, this analysis does identify at least one clear source of non-trivial error (accounting for 6.4\%) when performing standard frequency response analysis.

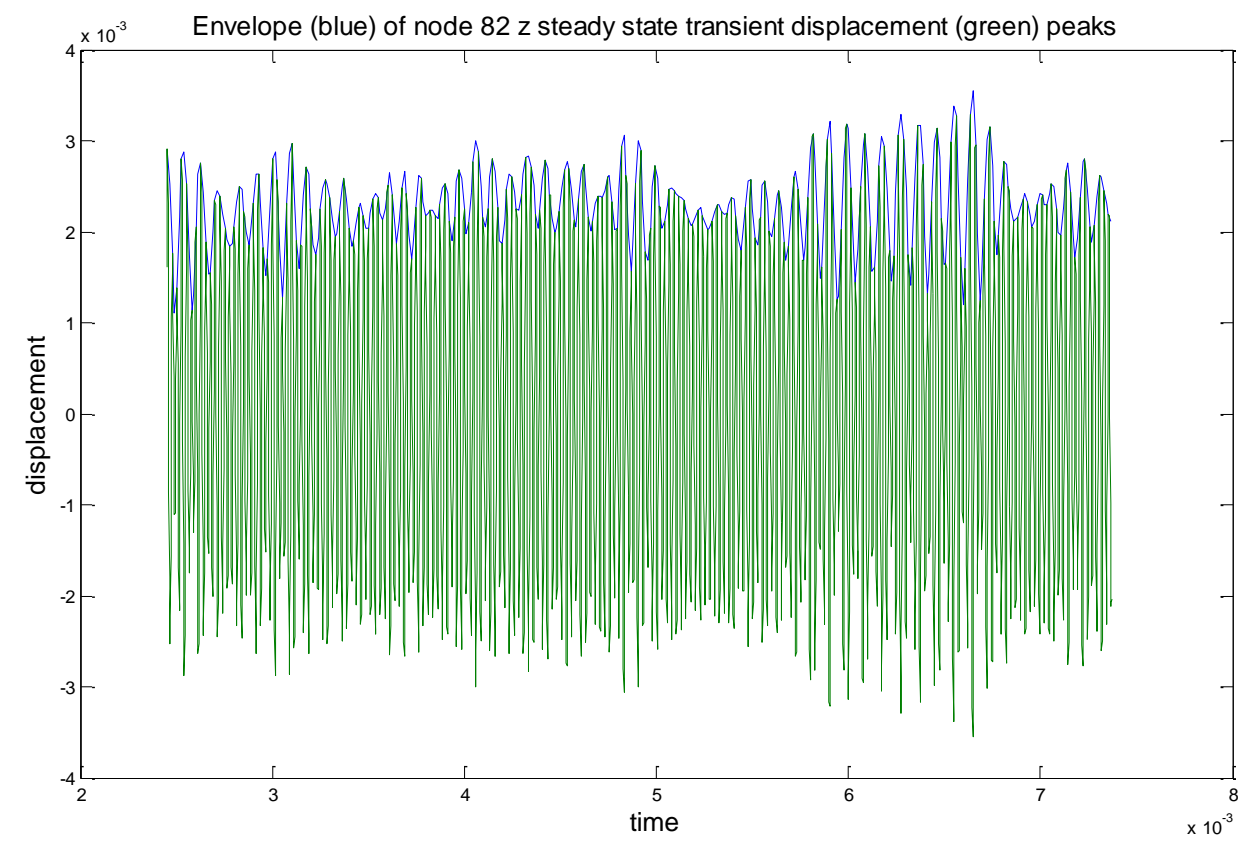

Figure 3. Peak Transient Analysis Response of Highest Responding Node in Beam/Plate Model 


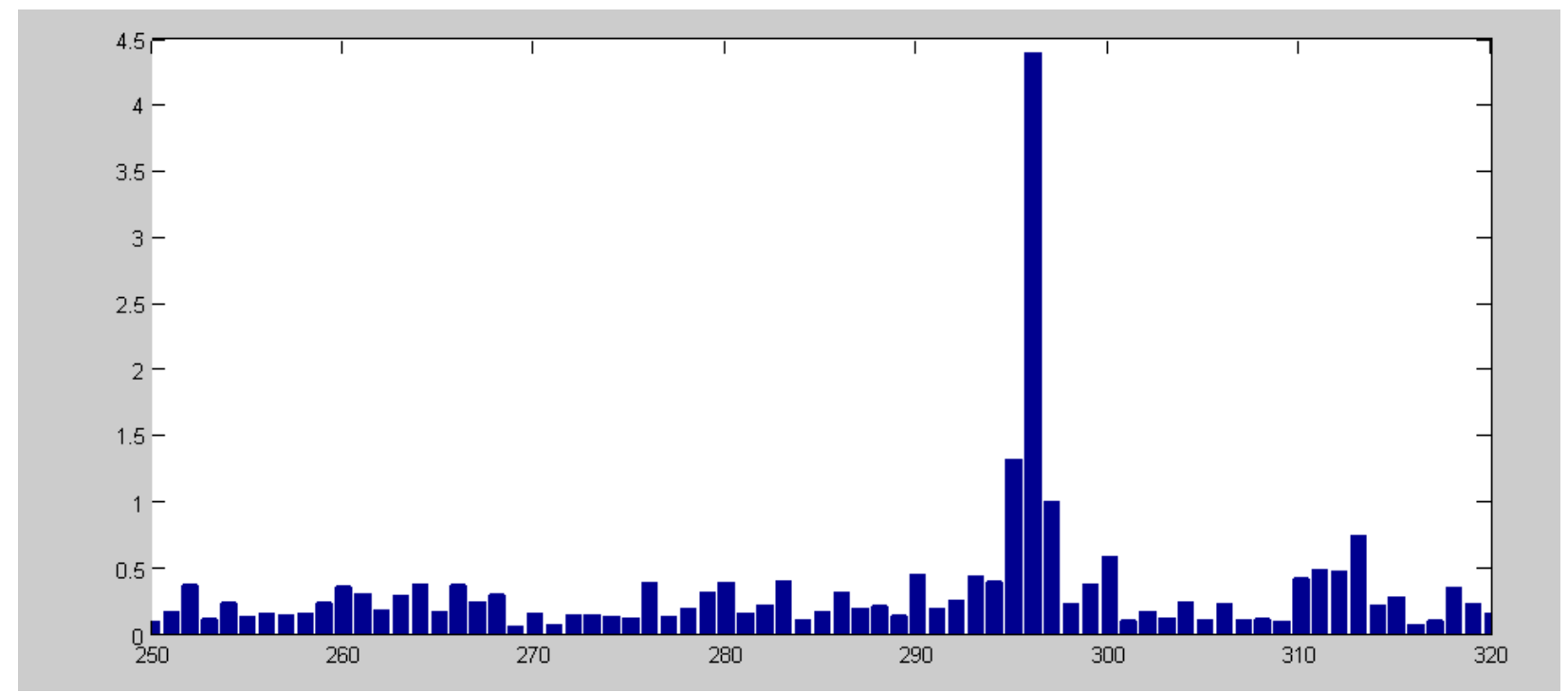

Figure 4. Magnitude of loading from sidebands of fundamental excitation in bin 296.

\section{B. Realistic Airfoil Solid Model Analyses - 74N Excitation of 5nd Mode}

The second phase of the research program was motivated by the question of what the effect of slightly aperiodic excitation would be on blade-dominated modes, rather than the nodal diameter dominated modes of the beam/plate model. This required the construction of a solid element bladed-disk model with a representative airfoil. As before, a $360^{\circ}$ model was built to be able to readily load it with the same $360^{\circ}$ CFD loading as used in the $\mathrm{J} 2 \mathrm{X}$ engine program (five complete revolutions). The model was quite large, as shown in Fig. 5, but was made manageable by using the new glued-contact formulation in MSC/NASTRAN, which enables a much simpler model of the disk than of the blades by allowing dissimilar meshes at the interface. Once again, for this case, it was hypothesized that the frequency response would overestimate the transient because the requirement that the spatial distribution of the loading on each blade matches the mode shape would be made artificially periodic. A modal analysis was first performed and the 5ND mode at 40,264 hz was identified for resonant excitation (see Fig. 6).

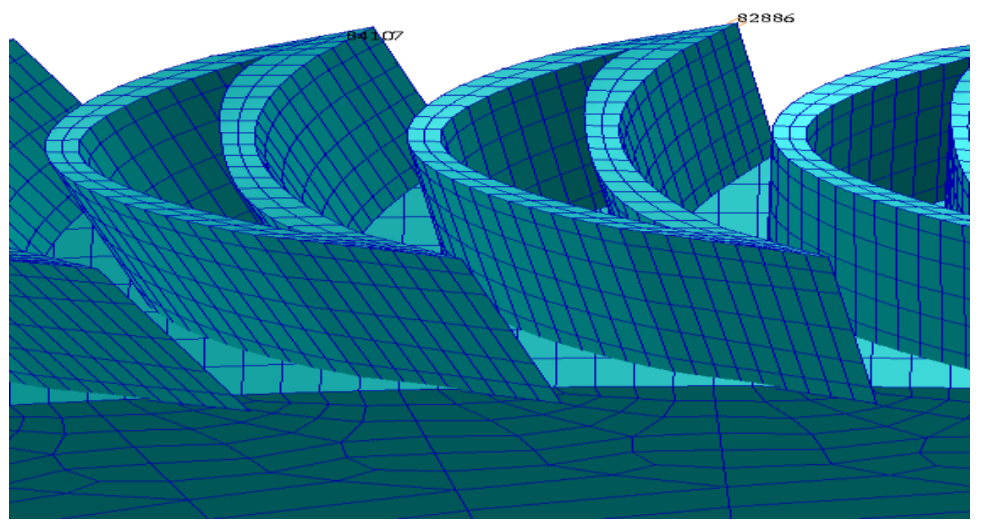

Figure 5. Solid Element Representative Bladed-Disk Model (not to scale) 


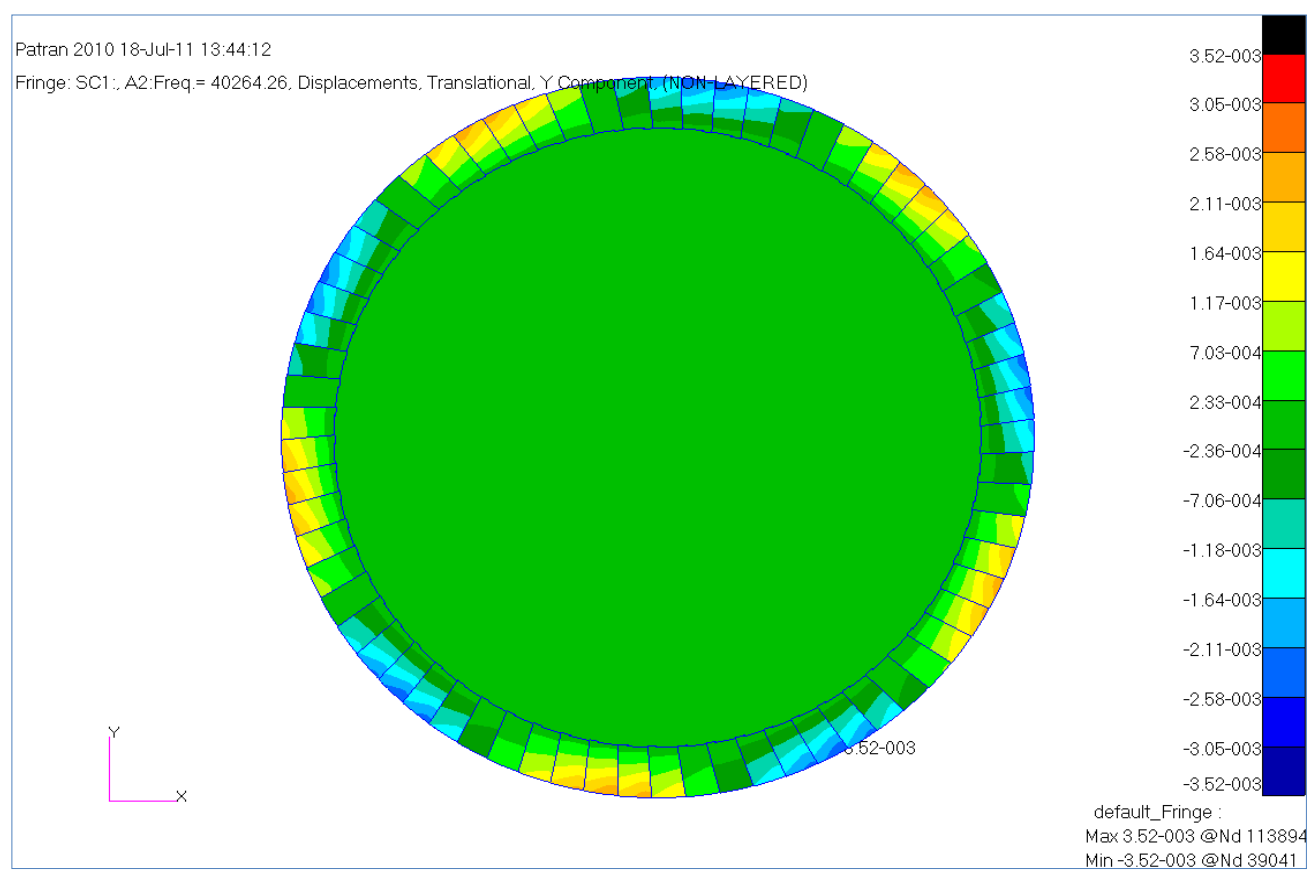

Figure 6. Realistic Airfoil Solid Blade-Disk Model 5 Nodal Diameter Mode at 40,264 hz

The next step was to perform the frequency response analysis for the 5ND mode. Plots of the entire ring of outermost nodes of the blades at different frequencies within the analysis band were generated and the maximum responding node for each case identified (Fig. 7). Graphs of the response of those nodes in the entire band were then generated (Fig. 8), and the peak response of the peak responding node was tabulated.

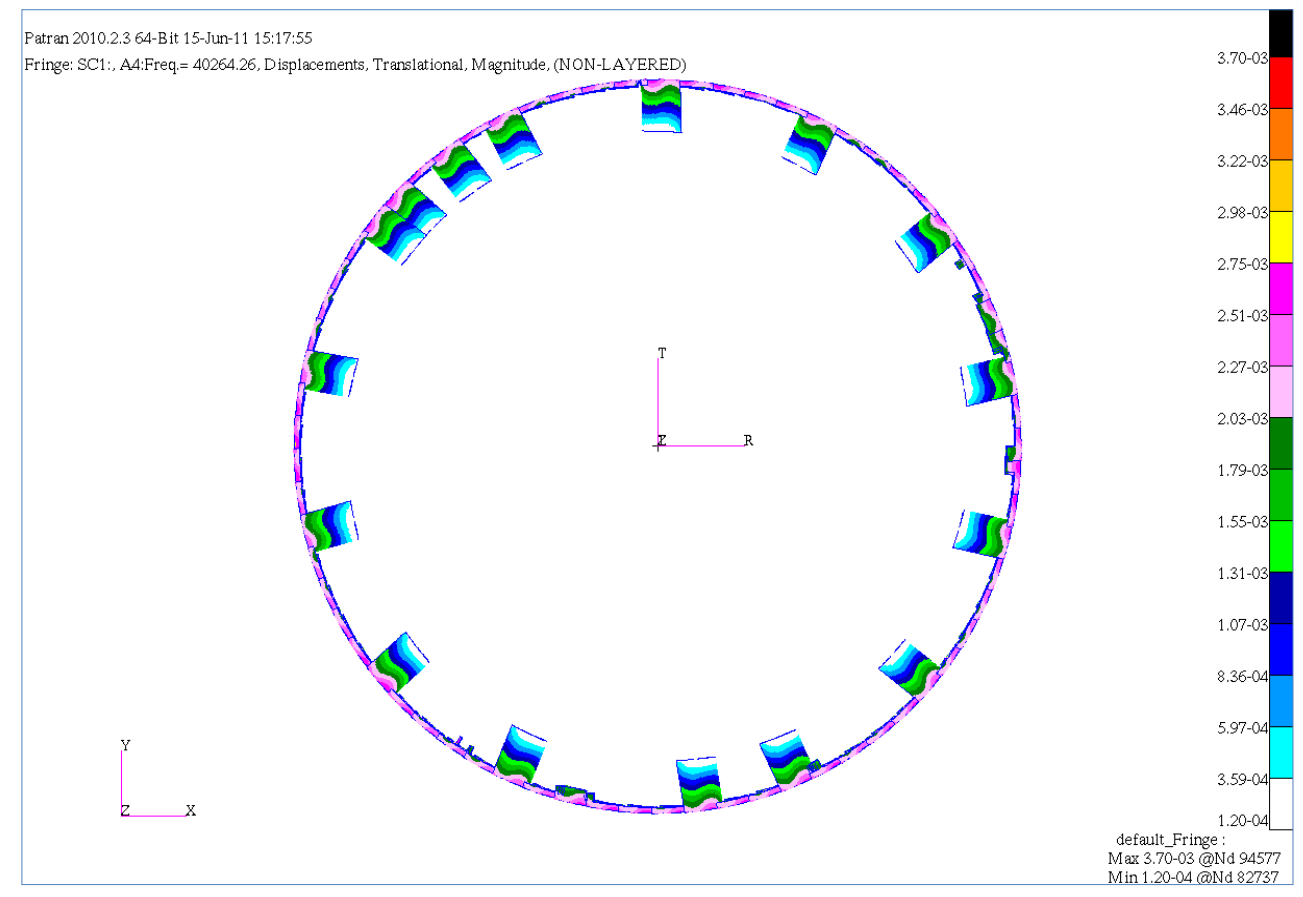

Figure 7. Frequency Response of Outermost Nodes to Harmonic Excitation at 40,264 hz 


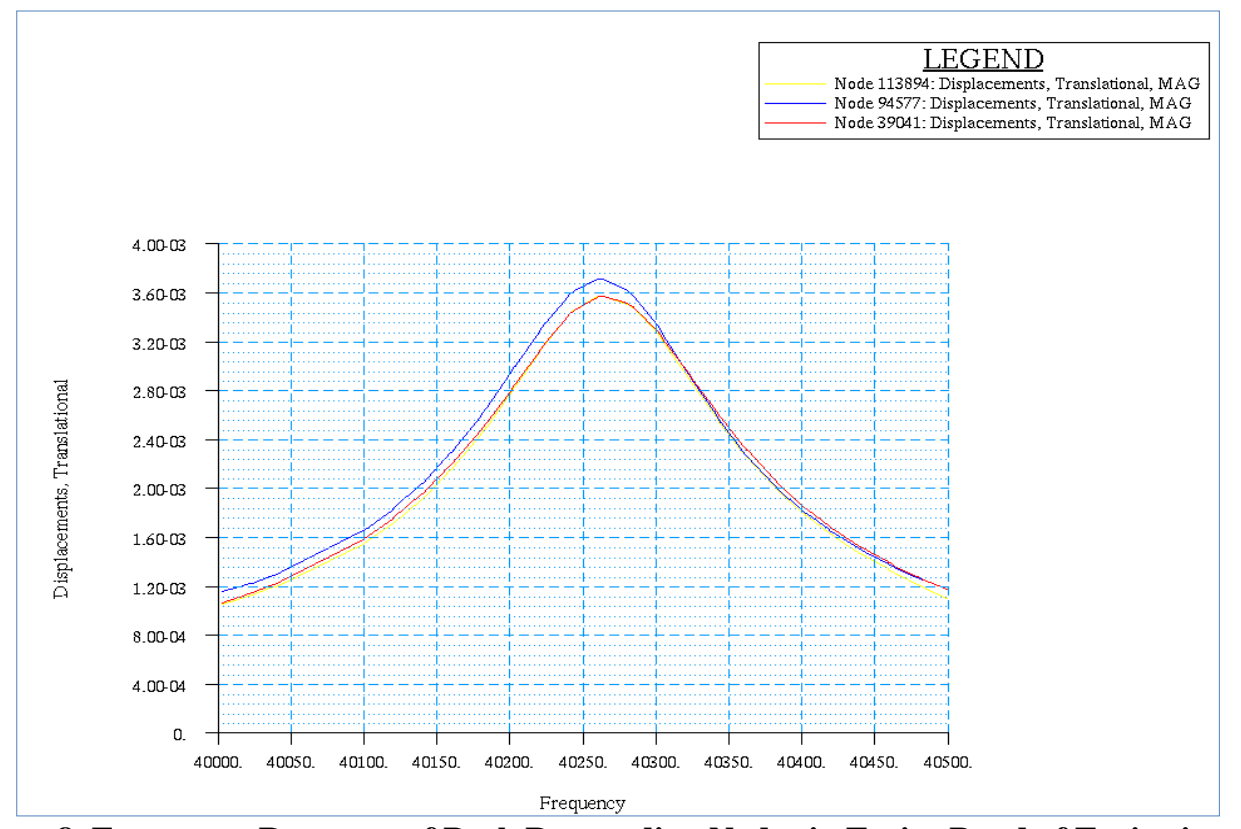

Figure 8. Frequency Response of Peak Responding Nodes in Entire Band of Excitation.

The transient analysis examining the 5ND mode was then performed, and even with the mesh-reduction described previously, it was still tremendously CPU-intensive as a temporal loading for each of 29,000 grids on the blades was applied to the model. Each transient run took approximately 84 clock hours to run on a Linux server. Time histories of the nodes identified from the frequency response analysis were created, and the comparison values were obtained by identifying the time of maximum peak-to-peak oscillations of the response and dividing by two (Fig. 9).

The final comparison of the peak nodes is shown in Table 2. In addition to the output from the 74N frequency response run, the output amplitudes from the sidebands at $73.8 \mathrm{~N}$ and $74.2 \mathrm{~N}$ are also included, as well as the maximum value when the responses are added. For this case, adding the sidebands moves the results to within an acceptable error, with four out of the five nodes examined having an error of less than $5 \%$. The mean $+2 \sigma$ calculation was performed only for the highest responding node, 83711, resulting in .00381 ", $6.8 \%$ less than the summed frequency response value of .00409 .

Table 2. Results for Frequency and Transient Analysis for Full Airfoil Solid Model Excitation of 5ND Mode

\begin{tabular}{|c|c|c|c|c|c|c|c|c|}
\hline Node & $\begin{array}{l}\text { Transient } \\
\text { Response } \\
\text { Theta } \\
\text { Displace- } \\
\text { ment }\end{array}$ & $\begin{array}{l}74 \mathrm{~N} \\
\text { Frequency } \\
\text { Response } \\
\text { Magnitude } \\
\text { Displace- } \\
\text { ment }\end{array}$ & $\begin{array}{l}74 \mathrm{~N} \\
\text { Frequency } \\
\text { Response } \\
\text { Theta } \\
\text { Displace- } \\
\text { ment }\end{array}$ & $\begin{array}{l}\text { Error } 74 \mathrm{~N} \\
\text { Freq Resp } \\
\text { from } \\
\text { Transient } \\
\text { Theta }\end{array}$ & $\begin{array}{l}73.8 \mathrm{~N} \\
\text { Frequency } \\
\text { Response } \\
\text { Theta } \\
\text { Dispace- } \\
\text { ment }\end{array}$ & $\begin{array}{l}74.2 \mathrm{~N} \\
\text { Frequency } \\
\text { Response } \\
\text { Theta } \\
\text { Dispace- } \\
\text { ment }\end{array}$ & $\begin{array}{l}\text { Peak of } \\
\text { sum of } \\
74 \mathrm{~N}, \\
73.8 \mathrm{~N}, \\
\text { and } 74.2 \mathrm{~N}\end{array}$ & $\begin{array}{l}\text { Error } \\
\text { sum } \\
\text { Freq } \\
\text { Resp } \\
\text { from } \\
\text { Trans- } \\
\text { ient } \\
\text { Theta }\end{array}$ \\
\hline 113894 & .00380 & .00358 & .00358 & $6 \%$ & .000658 & .000732 & .00415 & $9 \%$ \\
\hline 94577 & .00403 & .0037 & .00366 & $9 \%$ & .000606 & .000668 & .00421 & $5 \%$ \\
\hline 39041 & .00398 & .00358 & .00353 & $11 \%$ & .000694 & .000772 & .00414 & $4 \%$ \\
\hline 52320 & .004 & .00345 & .00357 & $11 \%$ & .000666 & .000740 & .00415 & $4 \%$ \\
\hline 83711 & .0042 & .00355 & .00352 & $16 \%$ & .000695 & .000664 & .00409 & $-3 \%$ \\
\hline
\end{tabular}




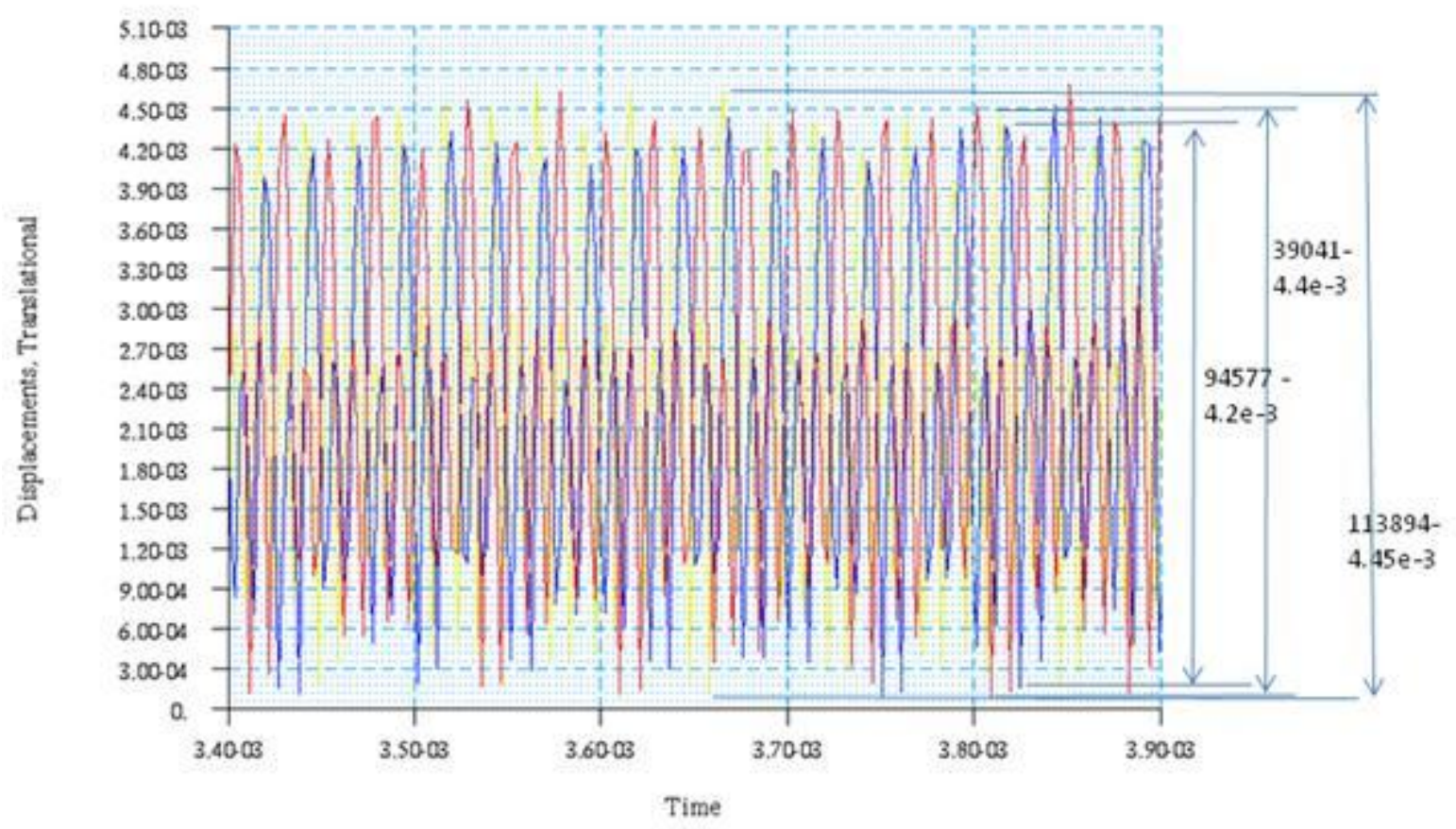

Figure 9. Full Airfoil Solid Model Transient Analysis Displacement Response, 74N=40264hz excitation

\section{57N Excitation of 12nd Mode}

Since the $12 \mathrm{ND}$ family will be excited by the $1^{\text {st }}$ multiple of the downstream stators as identified in Table 1 , a 12ND mode at 40,883 hz (see Fig. 10) was also identified from the modal run for response analysis. The results, shown in Table 3, are substantially different from the 5ND case. Running the analysis for five revolutions with the amplitude of excitation equal to the $285^{\text {th }}$ bin (five times the $57 \mathrm{~N}$ excitation), the frequency response results are up to $73 \%$ less than the mean-to-peak transient results (Fig. 11). If the $2 \sigma$ value obtained from the Rayleigh distribution of the peaks is used, this value was calculated to be $6.52 * 10^{-4}$ for the peak responding node, number 82462 ; this is still well over twice the peak value of the frequency response for that node. An investigation was initiated to attempt to explain this huge and potentially significant discrepancy.

Initially, as with the $5 \mathrm{ND}$ case, the effect of the non-integer $\mathrm{N}$-multiple sidebands of the $57 \mathrm{~N}$ present in the 5 revolution pressure excitation is examined. Rather than calculate the effects individually, though, a conservative analysis is to just perform the frequency analysis for the 1 revolution case, where all the sideband energy is inherently lumped into a single, $57^{\text {th }}$ bin. The results from this analysis are also shown in Table 3 , and do show some improvement, but the results are still significantly different than the transient results.

The second pertinent piece of data evaluated is that the energy on the blade leading edge (LE) is at least an order of magnitude larger than on the trailing edge (TE), as seen on plots of the temporally fourier-decomposed pressures (Fig. 12). Even at the 57N, which is a direct multiple of the downstream stator count, the leading edge $57 \mathrm{~N}$ content is much higher. Although the effect of any downstream obstruction will always be much less than the effect of upstream flow distortions, the asymmetries and supersonic conditions of this turbine introduce substantially denser fourier content than previously assumed. As a result, the 12ND shape dominates the trailing edge excitation spatial field at $57 \mathrm{~N}$, but the noise and asymmetric effects on the leading edge are of the same magnitude as the TE 12ND at other ND's, and in particular the -32ND shape at the LE, as shown in a spatial fourier decomposition of the 57N temporal fourier component (Fig. 13). 
Table 3. Results for Frequency and Transient Analysis for Full Airfoil Solid Model Excitation of 12ND Mode

\begin{tabular}{|r|l|l|l|l|l|l|l|l|}
\hline Location & Node & $\begin{array}{l}\text { Transient } \\
\text { Response, } \\
\text { theta, 5 } \\
\text { revs, } \\
\text { excitation } \\
40882.5 \mathrm{hz}\end{array}$ & $\begin{array}{l}\text { Frequency } \\
\text { Response } \\
57 \mathrm{~N}, 5 \\
\text { revs, } \\
285 \text { th bin } \\
(5 * 57 \mathrm{~N})\end{array}$ & $\begin{array}{l}\text { Error } \\
\text { from } \\
\text { transi } \\
- \text {-ent }\end{array}$ & $\begin{array}{l}\text { Frequency } \\
\text { Response } \\
57 \mathrm{~N}, 1 \\
\text { rev, 57th } \\
\text { bin }\end{array}$ & $\begin{array}{l}\text { Error } \\
\text { from } \\
\text { transi- } \\
\text { ent }\end{array}$ & $\begin{array}{l}\text { Frequency } \\
\text { Response } \\
\text { bin64 at } \\
45903 \mathrm{hz} \\
\text { theta disp }\end{array}$ & $\begin{array}{l}\text { Frequency } \\
\text { Response } \\
\text { bin 63 at } \\
45186\end{array}$ \\
\hline $\begin{array}{r}\text { Close to mid- } \\
\text { chord }\end{array}$ & 35378 & $7.25 \mathrm{E}-04$ & $2.02 \mathrm{E}-04$ & $-72 \%$ & $4.55 \mathrm{E}-04$ & $-37 \%$ & $6.50 \mathrm{E}-05$ & $1.90 \mathrm{E}-05$ \\
\hline $\begin{array}{r}\text { Close to mid- } \\
\text { chord }\end{array}$ & 36585 & $7.35 \mathrm{E}-04$ & $2.00 \mathrm{E}-04$ & $-73 \%$ & $4.64 \mathrm{E}-04$ & $-37 \%$ & $4.17 \mathrm{E}-05$ & $1.59 \mathrm{E}-05$ \\
\hline $\begin{array}{r}\text { Mid-chord } \\
\hline \begin{array}{r}\text { Close to mid- } \\
\text { chord }\end{array}\end{array}$ & 110229 & $7.35 \mathrm{E}-04$ & $2.80 \mathrm{E}-04$ & $-62 \%$ & $1.83 \mathrm{E}-04$ & $-75 \%$ & $5.01 \mathrm{E}-05$ & $2.12 \mathrm{E}-05$ \\
\hline close to mid-chord & 93537 & $5.60 \mathrm{E}-04$ & & & $4.09 \mathrm{E}-04$ & $-27 \%$ & $1.76 \mathrm{E}-04$ & $3.29 \mathrm{E}-05$ \\
\hline $\begin{array}{r}\text { Largest transient } \\
\text { of mid-chord }\end{array}$ & 86507 & $3.81 \mathrm{E}-04$ & & & $2.60 \mathrm{E}-05$ & $-93 \%$ & $1.01 \mathrm{E}-04$ & $4.30 \mathrm{E}-05$ \\
\hline Mid-chord & 97375 & $3.70 \mathrm{E}-04$ & & & $7.40 \mathrm{E}-05$ & $-80 \%$ & $6.16 \mathrm{E}-05$ & $3.03 \mathrm{E}-05$ \\
\hline Mid-chord & 85300 & $3.80 \mathrm{E}-04$ & & & $4.84 \mathrm{E}-05$ & $-87 \%$ & $5.53 \mathrm{E}-05$ & $3.83 \mathrm{E}-05$ \\
\hline
\end{tabular}
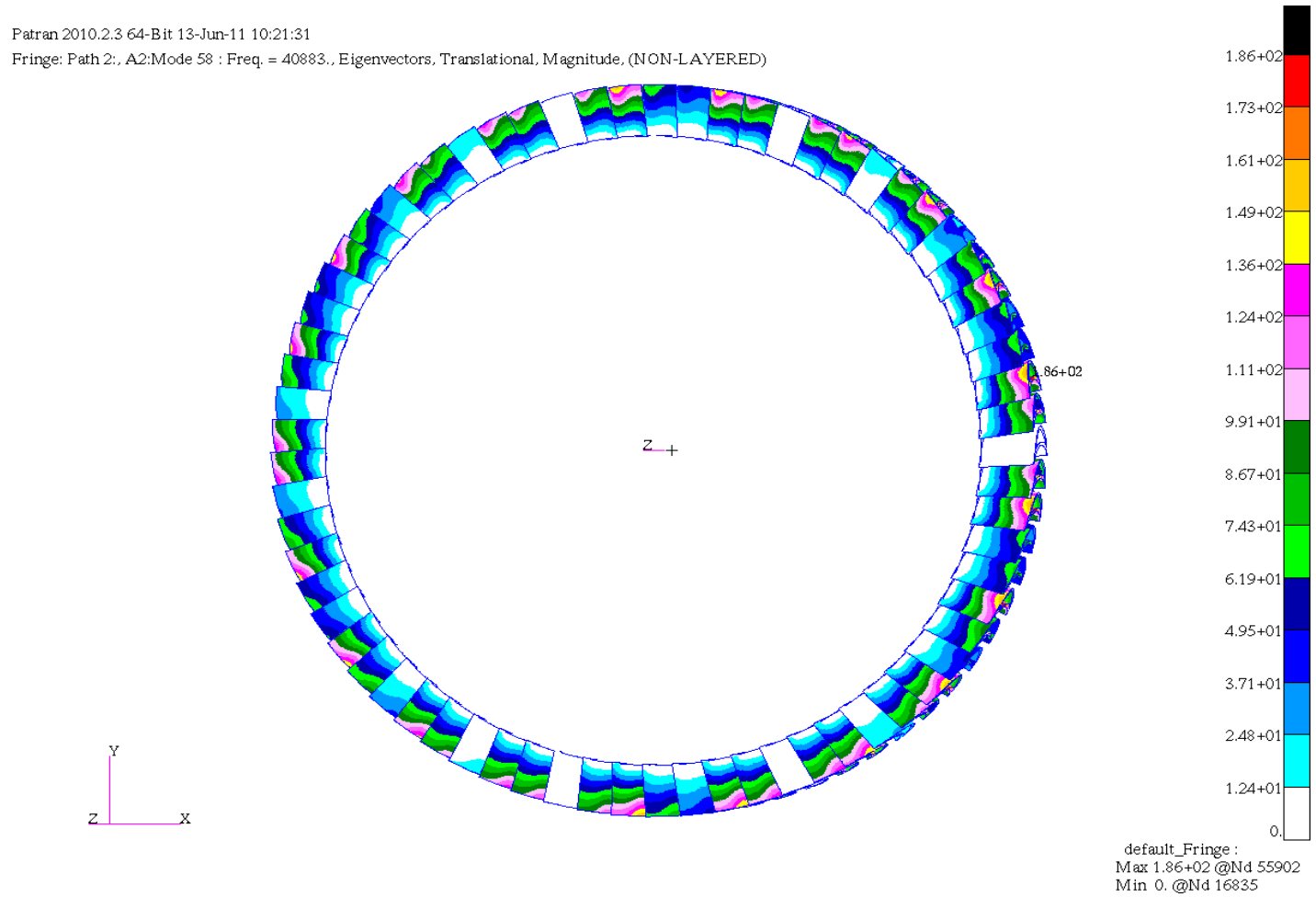

Figure 10. 12 Nodal Diameter shape at $40,883 \mathrm{hz}$ 


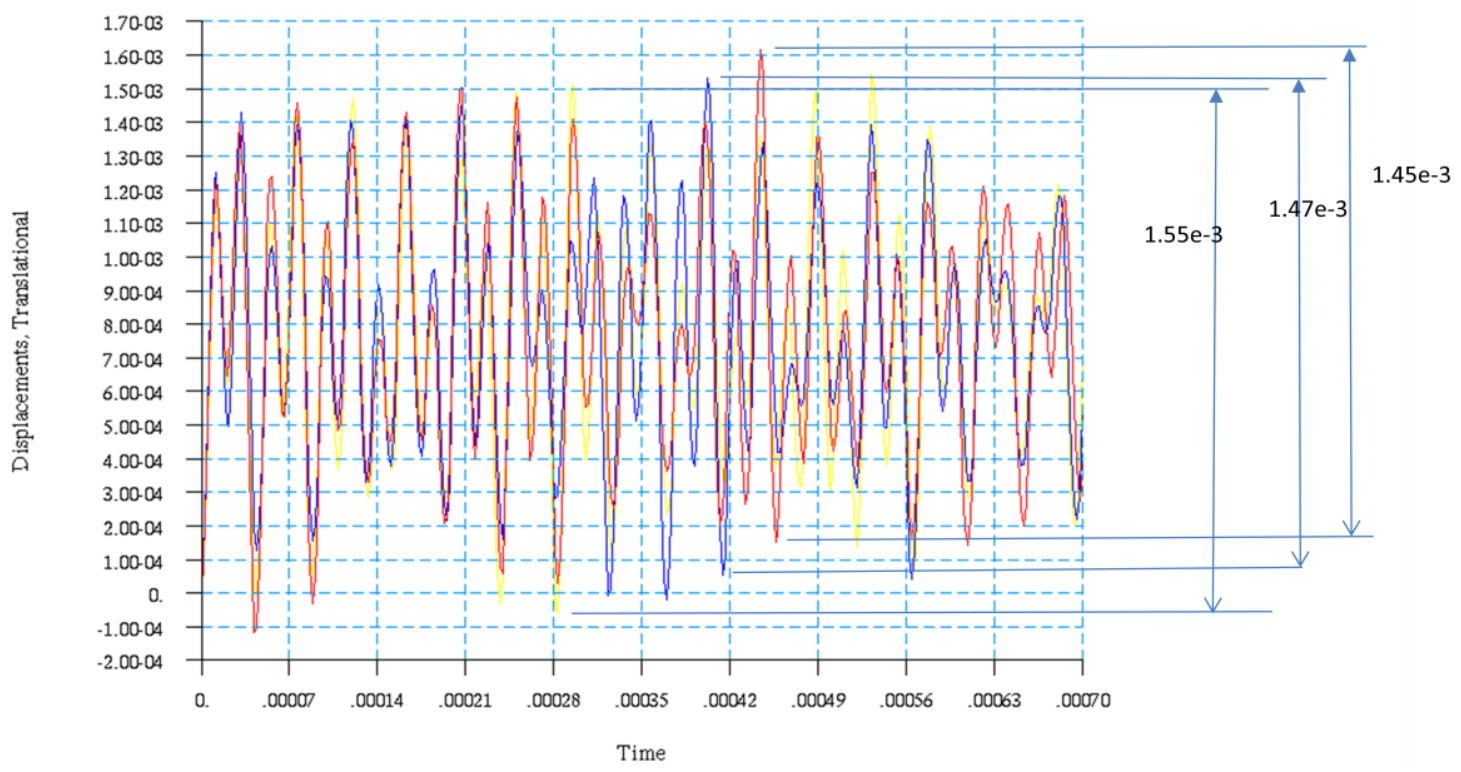

Figure 11. Transient Response for 12ND Excitation

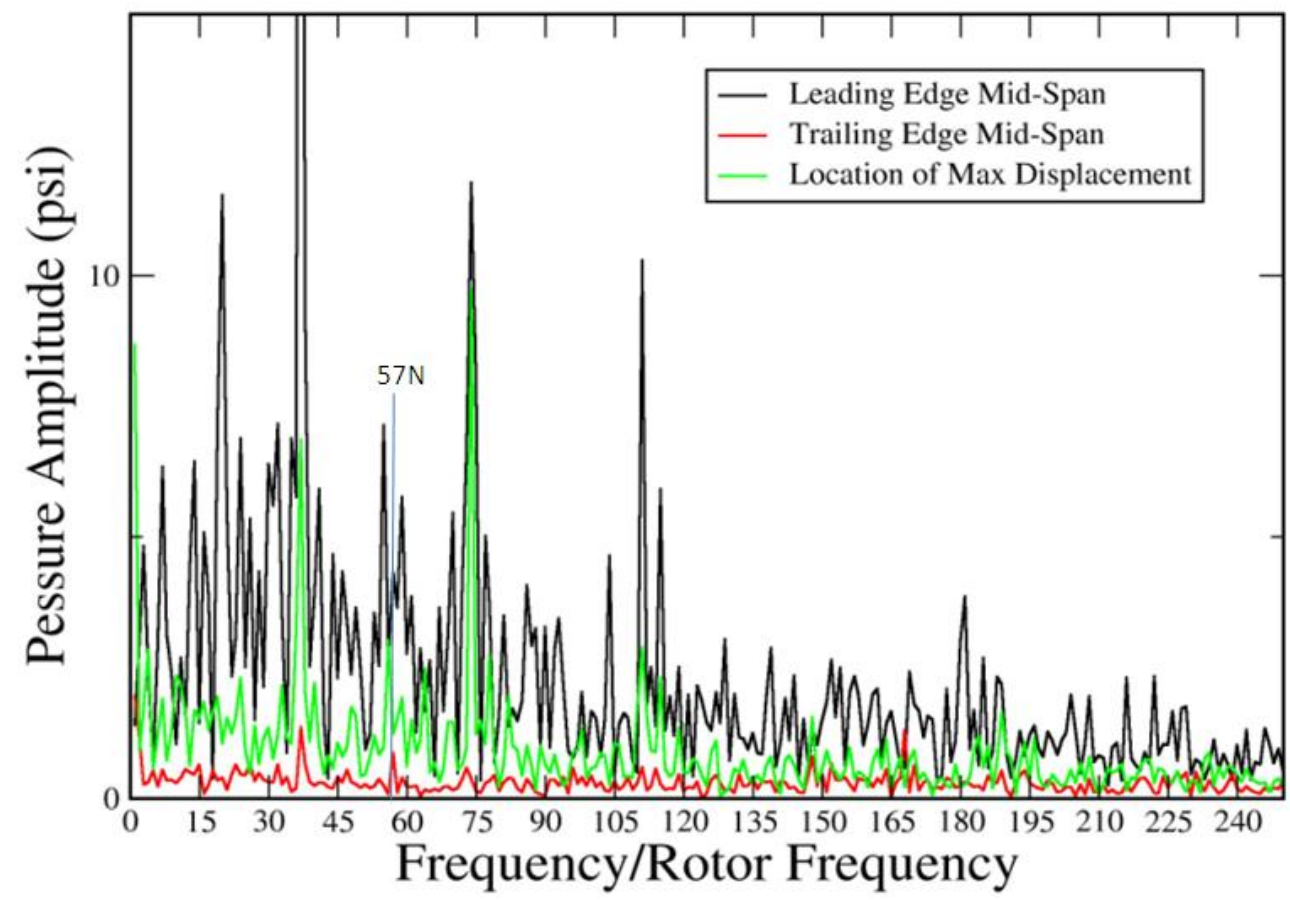

Figure 12. Temporal Fourier Decomposition of Pressures on selected Leading Edge, Trailing Edge, and Maximum Displacement Nodes

10

American Institute of Aeronautics and Astronautics 


\section{N Nodal Diameter Forcing Functions}

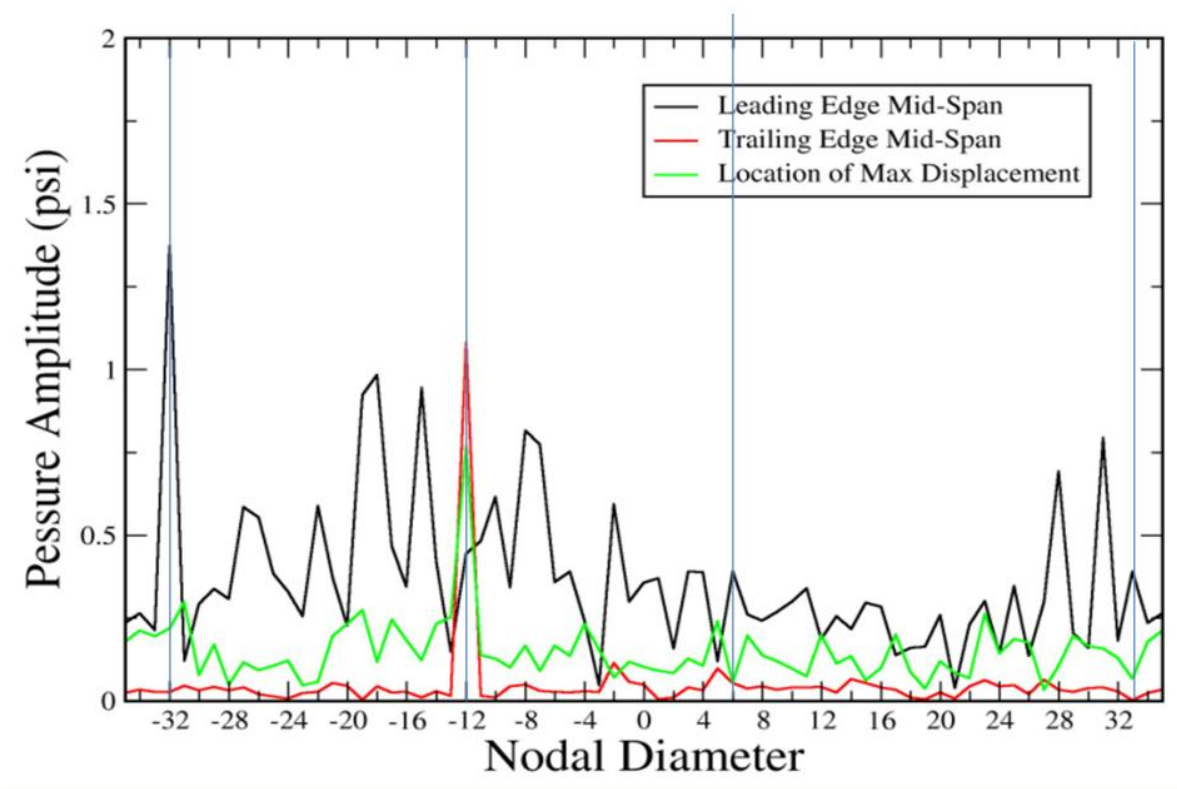

\section{Figure 13. Spatial Fourier Decomposition of the 57N Temporal Fourier Component of the Flow-Field}

In addition, the transient response peaks are not nearly as narrow-banded as the 5ND results, as shown in the wide variability of response in Fig. 11. A fourier transform of the transient response of the peak responding node 82462 shows significant energy at frequencies other than the 57N, as shown in Fig. 14. In effect, the typical SDOF oscillator filtering mechanism that converts narrow-to-wide band excitation into single-band response is quite weak in this case. A probable cause of the discrepancy, therefore, can be hypothesized by combining this information with the fact that the flow field has significant spatial density at nodal diameter modes other than 12ND. If the temporal field has frequencies at modes other than the $12 \mathrm{ND}$ at $40882 \mathrm{hz}$, and the spatial field also has content that matches these shapes as well, then the response at these frequencies could be significant and would not be seen in the response to the $57 \mathrm{~N}$ by itself.

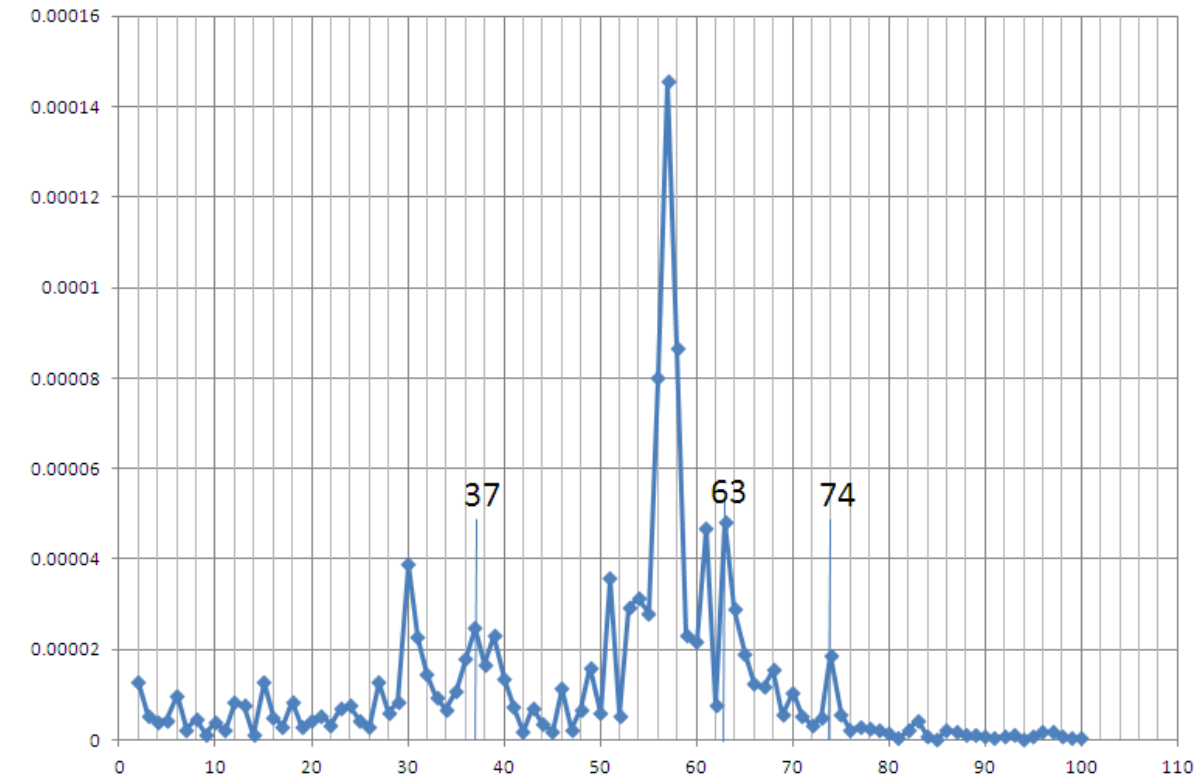

Figure 14. Temporal Fourier Transform of Transient Response of node 82462 for excitation such that $57 \mathrm{~N}=40883 \mathrm{hz}$

11

American Institute of Aeronautics and Astronautics 
A method to examine this hypothesis is to first examine the spatial content of these non- $57 \mathrm{~N}$ peaks and potentially corresponding modes. Looking at the peak at $29 \mathrm{~N}$ at a frequency of $21,146 \mathrm{hz}$, there is a mode within 50 $\mathrm{hz}$, but the shape is in the concentric circle family, so a nodal diameter type excitation could not excite it (the existence of concentric shapes in the flow field has not been examined). For the peak at $63 \mathrm{~N}$ at $45208 \mathrm{hz}$, there is a higher-order nodal diameter mode shape close to that value that is difficult to classify. The contribution of this mode can be determined by applying the fourier content at $63 \mathrm{~N}$ in a frequency response analysis. Unfortunately, the resulting peak response is only $8.35^{*} 10^{\wedge}-5$, an order of magnitude smaller than the $12 \mathrm{ND}$ frequency response.

A true understanding of these results is finally achieved by focusing on the response of the mid-chord nodes, which are close to the peak response nodes for each blade. Transient time histories of the mid-chord nodes were generated and used to calculate both a 2D Fourier transform (Fig. 15) and individual temporal Fourier transforms (Fig. 16a-c). The 2-D transform is able to present how much of the response is composed of wave numbers as well as frequency content since the response of the same node on each blade will map out these waveforms. Fig. 15 shows that the response consists of a very large number of waveforms (ie, responses in nodal diameter shapes), and frequency content spread out between $57 \mathrm{~N}$ and $64 \mathrm{~N}$. Individual temporal transforms of some of these mid-side nodes show peaks at these two waves, and the response at $64 \mathrm{~N}$ is actually larger than $57 \mathrm{~N}$ for nodes 86507 and 85300. Frequency response analyses were then performed at the $64 \mathrm{~N}$ bin for these two nodes, and these results reflected the fourier transform. The critical implication is that if frequency response analyses for all the individual bins were performed, the sum would approach the peak value seen in the time histories. Because of the complexity of the response and of the mode shapes, the previous focus on apparent modes was misleading; the 2D transform of the response itself shows that it is composed of a very large combination of shapes. Also, it wasn't that the very small frequency response results for the $63 \mathrm{~N}$ and $64 \mathrm{~N}$ bins for the peak responding nodes were incorrect in some way, it was just that the frequency content is so dense that a few bins by themselves will not be able to sum up to the time history peak.

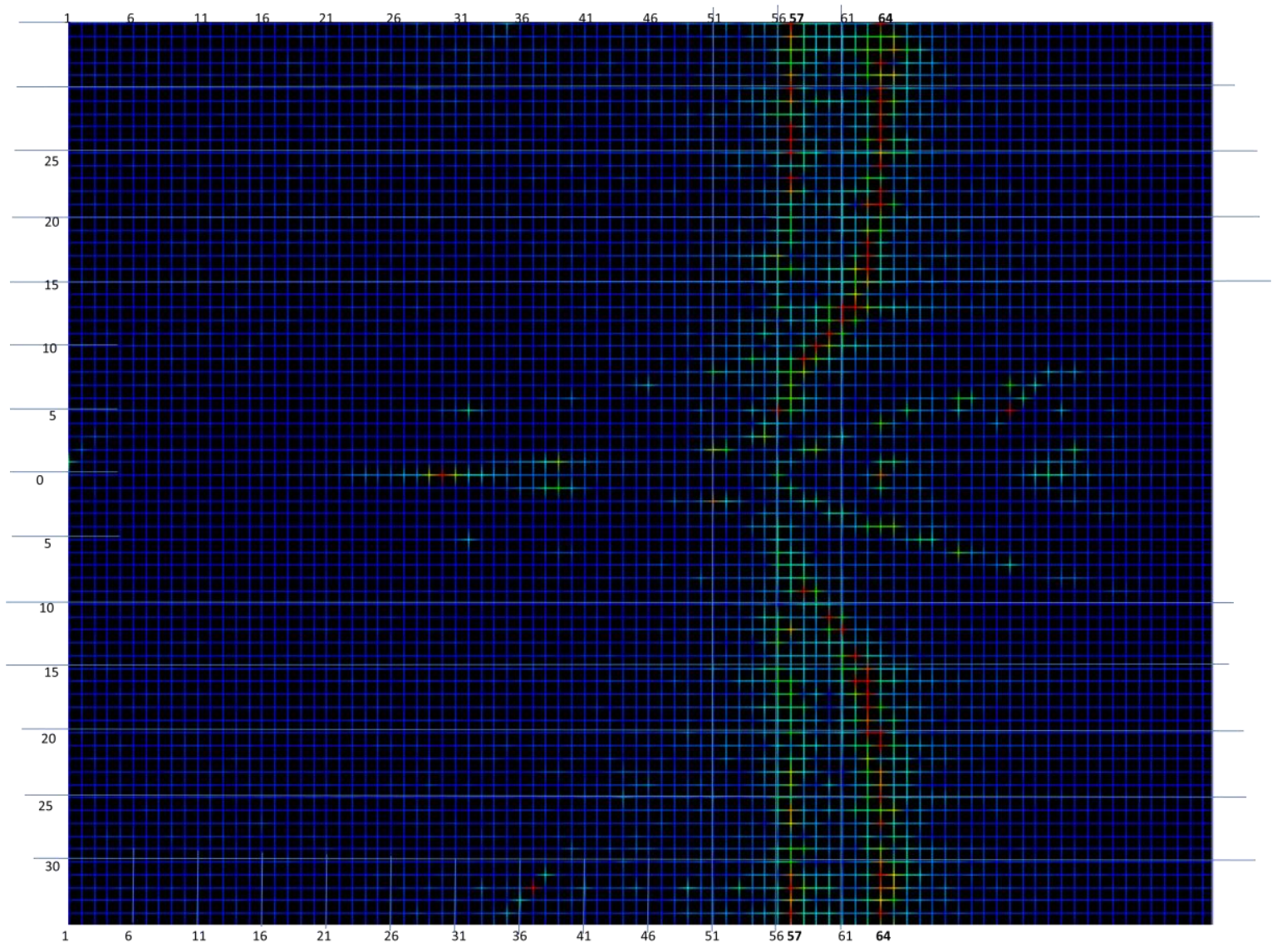

Figure 15. 2D (spatial and temporal) Fourier Transform of mid-chord nodes. 
a)

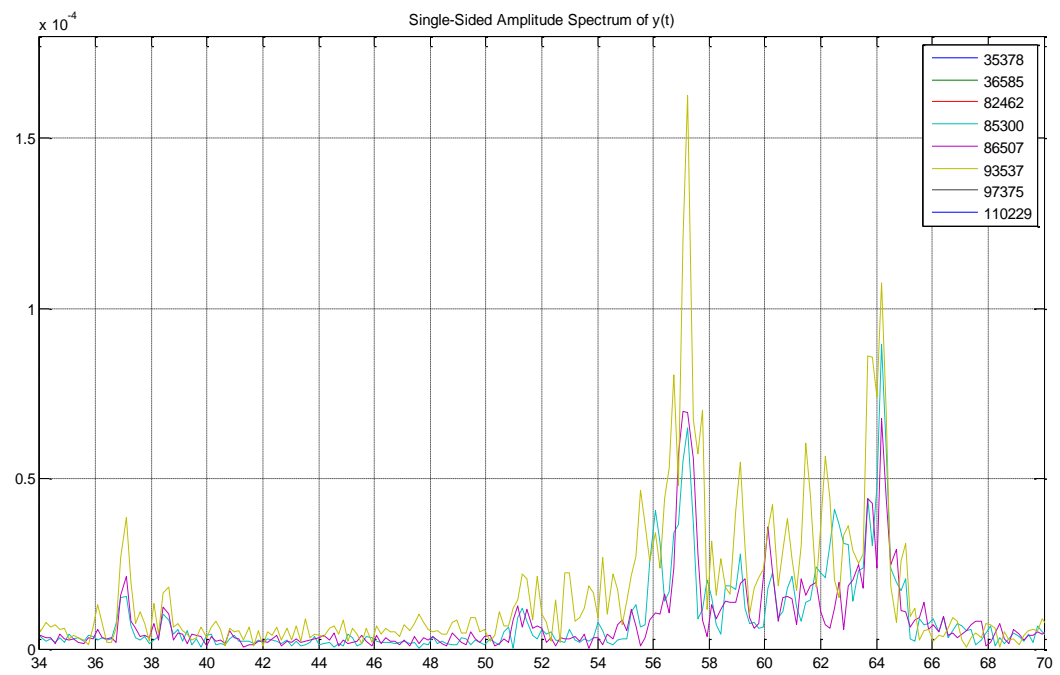

b)

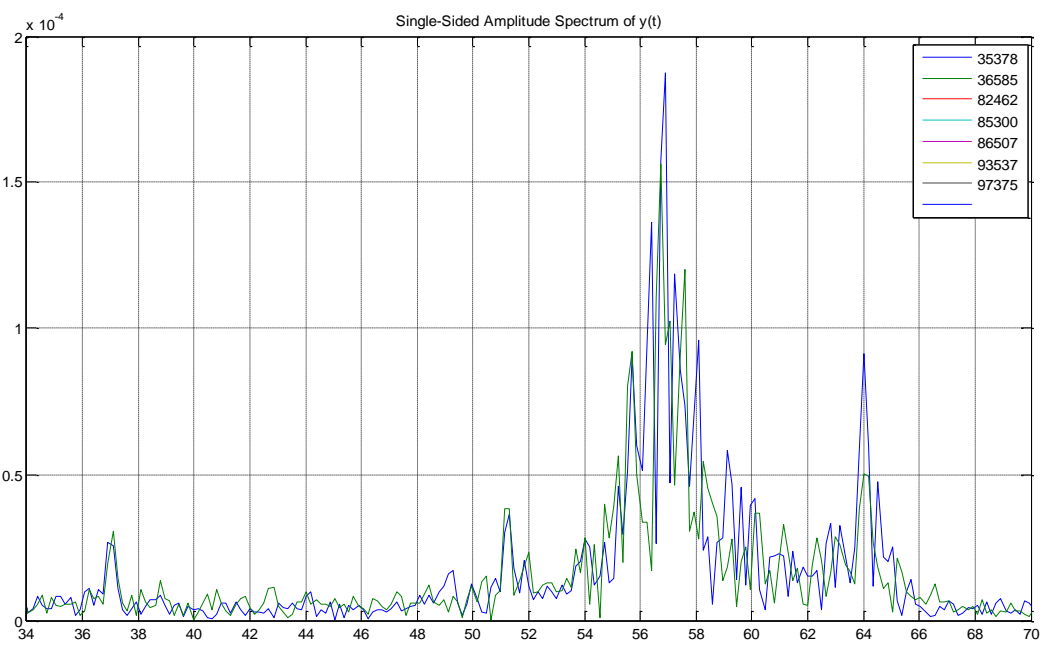

c)

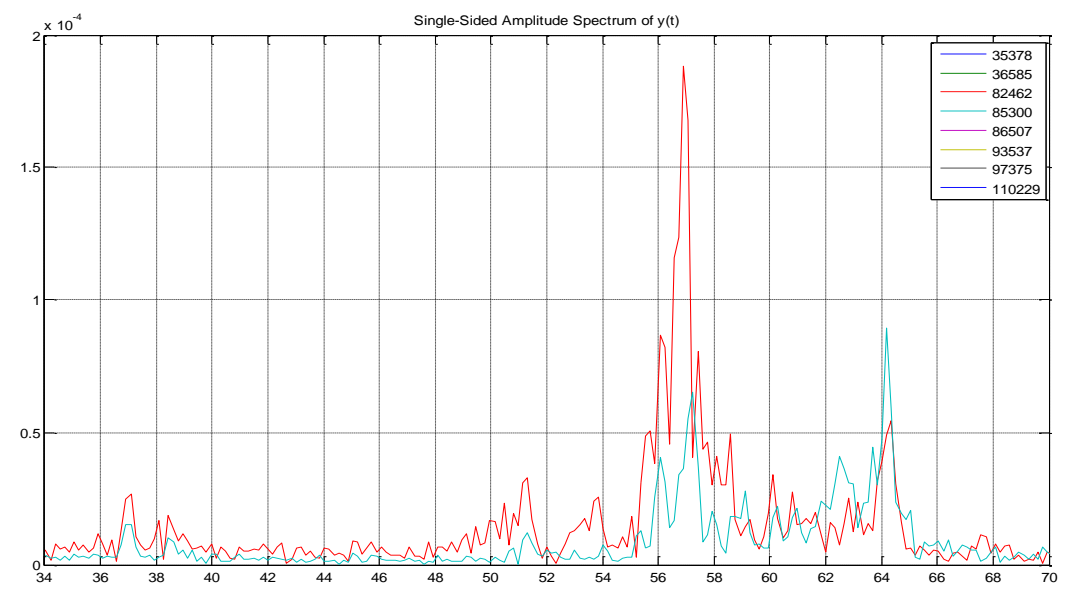

Figure 16. FFT's of a) nodes 82462 and 85300 ; b) nodes $93537,86507,85300$; c) nodes 35378,36585 
The conclusion of the investigation therefore is that content from many different temporal frequencies excites different modes, which are all captured in the time history response. A frequency response analysis can only capture the response to a single frequency excitation. To determine if this single frequency can accurately capture the entire response, therefore precluding a usually intractable transient response analysis, the Fourier content of the excitation needs to be closely examined, especially for "weak" drivers, such as this case where the pressure magnitude is overwhelmed by other drivers even at its excitation frequency, as shown in Fig. 12.

\section{Conclusions And Future Work}

An exhaustive study has been performed to characterize any possible deficiencies in the standard frequency response method of forced response analysis of bladed-disks. The time-marching transient analysis method has been chosen as a baseline for comparison. Two different models were analyzed; a very simple bladed-disk where the blades are modeled as simple beams, which was built to examine the differences due to the excitation of the disk type modes, and a more detailed solid model using the shape of the J2-X upper stage rocket engine fuel turbopump airfoil, which was intended on focusing on potential differences due to the blade mode shape excitation. The initial hypothesis that the frequency response would enforce a periodicity that would incorrectly magnify the response was usually incorrect. For cases where a strong exciting mechanism, such as an upstream flow distortion, excites the mode of concern, the difference between the techniques is less than $10 \%$ so is generally acceptable for design. In cases when the primary excitation mechanism is weaker though, the frequency response method indicates an underprediction error which can be enormous. For these situations, the existence of supersonic flow in asymmetric turbines causes significant variance in the cyclic symmetry of the excitation, which introduces spatial shapes in the flow other than those that normally exist due to blade-vane interaction. It appears that these shapes, combined with non-trivial temporal fourier content at frequencies other than at the primary driver, excite structural modes that would be ignored by the single frequency excitation used in frequency response analysis. The situation where a secondary, weak excitation source will be the primary driver of a design is rare but not unheard of, so the results of an initial frequency response calculation should be treated with significant conservatism, and transient analysis may be required to obtain accurate predictions.

\section{References}

${ }^{1}$ Elrod, D., Christensen, E., Brown, A., “Comprehensive Forced Response Analysis of J2X Turbine-bladed Discs with 360 Degree Variation in CFD Loading ”, JANNAF MSS/LPS/SPS Joint Subcommittee Meeting, Huntsville, Alabama, December 2011

${ }^{2}$ Misek, T., Tetiva, A., et. al, Prediction of High Cycle Fatigue Life of Steam Turbine Blading Based on Unsteady CFD and FEM Forced Response Calculation”, GT2007-278, ASME Turbo Expo 2007, May 14-17, Montreal, Canada

${ }^{3}$ Sever, I, Petrov, E., Ewins, D., Experimental and Numerical Investigation of Rotating Bladed Disk Forced Response Using Under-Platform Friction Dampers", GT2007-27307, ASME Turbo Expo 2007, May 14-17, Montreal, Canada

${ }^{4}$ Sipatov, A. M., et. al, “Tools For Estimating Resonant Stresses in Turbine Blades”, GT2007-27196, ASME Turbo Expo 2007, May 14-17, Montreal, Canada

${ }^{5}$ Tyler, J.M., Sofrin, T.G., Axial Flow Compressor Noise Studies, SAE Transactions, Vol. 70, 1961,p. 309-332 